\title{
Revelando Contradições e Incorporando Melhores Práticas no Cuidado à Saúde Bucal de Idosos ${ }^{1}$
}

\author{
ANA LÚCIA SCHAEFER FERREIRA DE MELLO " \\ ALACOQUE LORENZINI ERDMANN
}

O presente artigo tem por objetivo apresentar e discutir as contradições no processo de cuidar da saúde bucal de idosos e indicar rumos para a superação dessas contradições, na perspectiva do cuidado complexo e da lógica da complexidade. A pesquisa em que está lastreado adotou o referencial metodológico da Teoria Fundamentada nos Dados (Grounded Theory). Participaram do estudo 19 pessoas, entre idosos residentes em ILP, seus cuidadores profissionais da Enfermagem, dirigentes dessas instituições, cirurgiões-dentistas e gestores de serviços públicos de saúde. A categoria central emergente corresponde ao processo "Promovendo o cuidado à saúde bucal do idoso a partir do contexto das instituições de longa permanência". Nele são identificados dois estágios, um em que as contradições no processo de cuidar da saúde bucal do idoso mantêm a precariedade do quadro epidemiológico e outro, superior, que incorpora melhores práticas de cuidado nas estruturas e nos processos que compõem a promoção do cuidado à saúde bucal dos idosos. Tratar os elementos que compõem a contradição, sem eliminá-los ou desconsiderá-los - ao contrário, tomando-os em conta, buscando melhorias contínuas -, possibilita a superação da contradição, contornando o obstáculo que ela representa. Por esse caminho, a adoção da postura de melhores práticas pode ser considerada como um metaponto de vista, externo ao sistema de cuidado à saúde bucal, capaz de viabilizar a ultrapassagem de um estágio de contradição como o aqui revelado.

Palavras-chave: Idoso; cuidado; saúde bucal; teoria da complexidade.

Recebido em: 17/07/2006.

Aprovado em: 27/10/2006. 


\section{A complexidade do cuidado à saúde bucal: considerações iniciais e percurso metodológico}

A gênese do cuidado encontra-se no desejo de perpetuar a vida. $\mathrm{O}$ descuidado, por sua vez, é a ameaça à vida. Ameaça gerada pela exacerbação, sem limites, do gozo da própria vida ou pela incapacidade de dar-lhe sentido em face da inexorabilidade da morte. Cuidado e descuidado convivem e marcam a trajetória da Humanidade. Os avanços e recuos das civilizações associam-se ao cuidado e ao descuidado, ambos compondo uma mesma tela, contraditórios, mas fios de uma trama.

Os contornos não definidos, a plausibilidade no lugar da certeza, a instabilidade de sua produção no seio das organizações da saúde, a repetição regular de modos irregulares, as descontinuidades, conferem ao cuidado um caráter complexo, não-linear. Portanto, compreendê-lo, expressar seu significado e articular as práticas que lhe são subjacentes requerem pensamento compreensivo, aberto (MELLO, 2005). Exige visualizá-lo e entendê-lo como sistema complexo nas suas estruturas e propriedades. Apreciá-lo nos espaços das organizações complexas, onde ele é serviço-resultado, como sistema formado por elementos em redes com suas interconexões e dotado de movimentos inter-retroativos.

Compreender o cuidado implica reconhecer processos auto-ecoorganizadores no seu interior - portanto, ver mais que um sistema funcionalista, mais que um sistema organicista, enxergar um verdadeiro sistema organizacionista. O cuidado há que ser visto como um processo de relações, interações, associações, retroações entre os seres, em vários planos. É tanto auto-organizador por meio das práticas e atitudes, como organizador do sistema de saúde a que pertence. Ademais, co-organiza-se em simbiose com outros sistemas sociais (ERDMANN, 1996).

Esta visão da complexidade do cuidado, segundo os aportes mais modernos da filosofia e da ciência, contribui para uma melhor aproximação do tema da saúde bucal dos idosos, aqui tratado. Este texto foi elaborado a partir de estudo sobre o desenvolvimento de um modelo teórico para abordagem do fenômeno do cuidado à saúde bucal de idosos no contexto das instituições de longa permanência (ILP), em suas várias dimensões: individual, profissional, institucional e político-organizacional (MELLO, 2005). A compreensão do significado desse fenômeno, por meio da interação dessas dimensões, mostrou a admissibilidade de um estágio qualitativamente superior ao atual, mediante a 
incorporação de melhores práticas de cuidado na perspectiva do viver e envelhecer com saúde bucal.

A pesquisa adotou o referencial metodológico da Teoria Fundamentada nos Dados, a Grounded Theory (GLASER; STRAUSS, 1967; GLASER; HOLTON, 2004; GLASER, 2005). Participaram do estudo 19 pessoas, distribuídas entre idosos residentes em ILP, seus cuidadores auxiliares e técnicos de enfermagem e enfermeiros, dirigentes dessas instituições, cirurgiões-dentistas e gestores de serviços públicos de saúde. Os dados foram coletados por meio de entrevistas abertas. As etapas de pesquisa referentes à codificação, amostragem e saturação teórica, ordenação e integração guiaram-se pelo procedimento da análise comparativa dos dados. A organização dos códigos construiu-se de acordo com suas propriedades, agrupando-se em componentes, subcategorias e categorias.

Por meio da inter-relação entre as categorias, evidenciadas pelos dados coletados, chegou-se a uma categoria central, eixo estruturante do modelo teórico e integradora das categorias analíticas. A categoria central emergente corresponde e configura um processo social básico: "promovendo o cuidado à saúde bucal do idoso a partir do contexto das instituições de longa permanência". Nele são identificados dois estágios: o primeiro, em que as contradições no processo de cuidar da saúde bucal do idoso mantêm a precariedade do quadro epidemiológico; e outro, superior, que incorpora a postura de melhoria contínua, traduzida em melhores práticas de cuidado nas estruturas e nos processos que compõem a promoção do cuidado à saúde bucal dos idosos. O primeiro estágio corresponde à situação prevalecente em boa parte da realidade local brasileira. Representa o estado de apatia em frente às contradições no processo de cuidar e as consequiências maléficas para a saúde bucal desse grupo.

O presente artigo, assim, tem por objetivo apresentar e discutir o primeiro estágio deste modelo: revelar as contradições no processo de cuidar da saúde bucal de idosos na perspectiva do cuidado complexo e da lógica da complexidade.

\section{A lógica da complexidade como referencial analítico da contradição}

As ações/interações associadas à realização das práticas de cuidado à saúde bucal dirigidas a idosos residentes em ILP são traduzidas numa série de contradições que se originam do significado construído/elaborado pelos 
participantes do estudo. Essas contradições perpassam propriedades, estruturas e dimensões do cuidado à saúde bucal, sendo evidenciadas, no plano individual e coletivo, entre indivíduos e instituições que, de uma forma ou de outra, cooperam (ou não) para a realização dessas práticas de cuidado. A análise das categorias constatou a presença de conceitos contraditórios, ambivalentes e antagônicos convivendo em harmonia conflitiva e convergindo para determinar os processos e as estruturas componentes do cuidado à saúde bucal do idoso institucionalizado.

O pensamento racional associa constantemente indução e dedução, e neste diálogo chega a conclusões fundamentais, utilizando simultaneamente o empirismo e a lógica. O procedimento indutivo estimula a observação, o estabelecimento de relações, a procura por correlações, e o procedimento dedutivo assegura a coerência teórica. Assim, ao apoiar-se no fundamento empírico natural trazido por uma, e no rigor lógico trazido pela outra, a ciência obtém a certeza de poder aproximar-se da verdade (MORIN, 1992 e 2005).

A lógica possui uma dupla natureza. Uma originada na computação, fonte operacional de todo conhecimento vivo e humano, constituindo um sistema simbólico que obedece a regras de cálculo como disjunção, conjunção, implicação, negação, entre outros. Entretanto, isso não significa excluir de todo o reconhecimento da sua realidade objetiva, que é noológica, ou seja, tem relação com a maquinaria cognitiva formal, associada à linguagem, possibilitando encarála como a estrutura formal do sistema de idéias, concebida na/pela consciência humana. Uma lógica institui a ordem e a regra computacional para todo pensamento e sistema de idéias. O conjunto de regras lógicas constitui uma norma intelectual que determina a construção de doutrinas, teorias e ideologias (MORIN, 1992).

A lógica hegemônica vigente tem origem em fundamentos estabelecidos por Aristóteles. O núcleo da lógica clássica incide na identidade, na dedução e na indução, que garantem a evidência, a coerência e a validade formal, tão necessárias e valorizadas nas teorias e discursos. Os axiomas da lógica clássica, ou dedutivo-identitária, são o princípio da identidade (impossibilidade de algo existir e não existir ao mesmo tempo), o princípio da não-contradição (impossibilidade de um mesmo atributo pertencer e não pertencer a algo/alguém) e do terceiro excluído (toda proposição dotada de significado é verdadeira ou falsa). Os três princípios são inseparáveis e solidários.

A ciência tradicionalmente repeliu a contradição, pois esses axiomas assumiram um valor universal e impensável de ser transgredido nos sistemas 
racionais. Influenciaram o modo de pensar e as conseqüências disso, principalmente por considerar fora da lógica, fora do mundo e fora da realidade tudo aquilo que ultrapassasse o limite desta coerência (MORIN, 1992 e 2005). A contradição seria o indício de um erro de raciocínio e por isso mesmo deveria não só ser eliminada, como ser eliminado o raciocínio que a ela conduzia. Sublinhese que a contradição referida neste estudo não é aquela advinda de um raciocínio incoerente ou de uma falta de racionalidade. Trata-se aqui da contradição que aparece fruto de premissas consistentes, oriundas de uma operação racional/ empírica de caráter científico.

Mas uma revolução silenciosa vem-se impondo ante o reconhecimento da fragilidade da lógica clássica em lidar com a contradição. A infalibilidade da lógica e a certeza científica são postas em xeque com o surgimento/ reconhecimento da incerteza e da contradição percebidas na Física, justamente no campo das ciências ditas exatas. Ao admitir-se a contradição pela racionalidade científica, fragilizam-se os paradigmas fundados nos princípios de identidade, de não-contradição e do terceiro excluído (MORIN, 2005).

A contradição efetivamente pode aparecer como atentado ao bom senso (paradoxo), como conflito entre duas proposições igualmente demonstráveis (antinomia), como afrontamento entre duas soluções incompatíveis uma com a outra (aporia) e mais amplamente como emparelhamento de dois termos que se excluem. A contradição torna-se então um escândalo no seio da lógica identitária, visto que induz a não-identidade na identidade, a pertença e a nãopertença de um atributo a um sujeito, e estabelece uma relação de exclusão e inclusão de dois termos, violando o princípio do terceiro excluído (MORIN, 1999).

O pensamento e o universo dos fenômenos são por si complexos. Há complexidade quando elementos diferentes são inseparáveis, constitutivos do todo. Há complexidade na relação interdependente, interativa e inter-retroativa entre o objeto de conhecimento e seu contexto (MORIN, 1999).

Por isso, já vai se tornando clássica a assertiva de Morin (1992), de que "toda introdução da contradição ou da incerteza pode transformar-se em ganho de complexidade". O reconhecimento da contradição na realidade revela os limites da lógica e a complexidade do real, configurando não uma falha ou derrota, mas o início de uma progressão para o saber, para a verdade. 


\section{Revelando as contradições no processo de cuidado à saúde bucal de idosos}

Definir o que são estados de saúde ou doença bucal nos idosos constitui um desafio na contradição que se estabelece dentro dos parâmetros que atualmente os configuram. Se o conceito de doença estiver meramente associado à presença de patologias, dor ou desconforto, então pode-se considerar saudável um idoso com a ausência desses problemas/condições. E a maioria deles assim se apresenta, devido à total falta de elementos dentários. Desfrutariam essas pessoas de saúde bucal? Seriam consideradas saudáveis? Não apresentar elemento dental algum é, para muitos idosos, sinal de alívio, visto que a perda dentária é considerada solução para os momentos de sofrimento vividos quando possuíam dentes. Pensando nas próteses, o próprio dispositivo que deve proporcionar benefício ao idoso, recuperando as funções mastigatórias e estéticas, ocasiona problemas caso não seja adequadamente higienizado. Seria melhor estar sem as próteses dentárias, caso não sejam cuidadas e acabem servindo para acúmulo de bactérias e fungos?

Esses conceitos ainda são mais contraditórios se ampliarmos a visão e inserirmos a questão da necessidade de cuidados à saúde bucal. As necessidades normativa e sentida são conceitos que geralmente estão em desarmonia e conflito entre profissionais da saúde e idosos. O que parece ser uma necessidade premente para o profissional nem sempre é assim entendido pelo idoso.

Ser/estar na condição de idoso institucionalizado revela a contradição da inclusão-exclusão dos idosos na sociedade. Ao ser resgatado pela instituição, o idoso é incluído, passando a receber atenção e cuidados específicos destinados àquelas pessoas que apresentam algum tipo de dependência, cuidados que garantam sua saúde e dignidade humana. No entanto, ser/estar institucionalizado é, via de regra, estar excluído do mundo, dos seus antigos relacionamentos, do seio familiar e domiciliar, excluído da intimidade de viver no espaço exclusivo do seu lar. A inclusão do ser idoso no viver coletivo confere-lhe viver a ausência de uma família idealizada no seu imaginário. Pelo fato de as ILP para idosos ficarem à margem, também excluídas de políticas públicas e, principalmente, de saúde bucal, o idoso institucionalizado encontra-se adicionalmente excluído do acesso à atenção e assistência odontológicas públicas. O Estado brasileiro, pela via dos serviços públicos de saúde, age passivamente, e assim se revela omisso no essencial, ao não reconhecer e atender às demandas presentes nas ILP para idosos. 
As práticas de cuidado à saúde bucal são entendidas tanto como meio como um fim em si mesmas. Ao significarem o modo pelo qual as pessoas, em geral, mantêm, previnem ou recuperam sua saúde bucal e até mesmo aspectos mais abrangentes da sua saúde, elas são observadas como meio. Todavia, ao não serem associadas a possibilidades futuras, ao se afastarem dos conceitos de saúde e cuidado, denotam uma ausência de significado/motivo na ação, esgotam-se em si mesmas. Essa falta de sentido corrói progressivamente a atitude de cuidado. Daí até a doença é um passo.

De um modo geral, os participantes idosos da pesquisa relacionam o cuidado à saúde bucal com hábitos, comportamentos, instituições e estruturas sociais, tornando esse cuidado um fazer próprio do seu modo de vida e trabalho. Entretanto, o cuidado à saúde bucal, quando não faz ou deixa de fazer parte significativa do viver cotidiano, torna-se uma idéia difusa, pois as pessoas não conseguem delimitar com precisão seus contornos e suas possibilidades. Não apresentam, não reconhecem o cuidado como um objeto passível de apreensão e controle tanto para si quanto para as instituições. Dessa forma, torna-se algo distante, sem significado/sentido e de pouca utilidade.

A abordagem do cuidado à saúde bucal contempla um plano geral e um plano particular, nem sempre congruentes, e às vezes implicando algum antagonismo. Num plano geral, o cuidado à saúde bucal equipara-se a outros procedimentos complexos. É importante e fundamental para a vida; mostra-se relevante para a manutenção da saúde; engloba abordagens multidisciplinares; é entendido como direito de todos os idosos e requer do Estado a implementação de políticas públicas para garanti-lo à população, por exemplo. Num plano mais particular, implica intervenções nas estruturas bucais; trata da elaboração de protocolos de procedimentos; compete com outras áreas de cuidado do corpo e da saúde; implica a formação de profissionais para praticá-lo; valoriza a Odontologia baseada em evidências, entre outros aspectos.

Outro dilema revelador das contradições presentes no processo de promoção do cuidado à saúde bucal do idoso aparece por ocasião da decisão/ adoção de determinado plano de tratamento, que, se de um lado objetiva combater a doença/patologia, de outro provoca efeitos colaterais negativos para a saúde bucal. No caminho inverso, também intervenções nas estruturas bucais, quando descoladas das condições e hábitos de vida do idoso, podem ocasionar consequiências indesejadas na sua saúde. 
A consciência, em maior ou menor grau, da importância do cuidado à saúde bucal do ser idoso reflete-se sobre a realização de suas respectivas práticas de cuidado. Ser consciente da necessidade, do valor do cuidado à saúde bucal e das conseqüências negativas que a falta de cuidado pode ocasionar na saúde e na vida dos idosos é condição determinante da efetivação e da qualidade dos procedimentos. Esta consciência, subjetiva e particular, é contraditada por ocasião da discussão das prioridades de atenção aos idosos em face da curta expectativa de vida. Nessa discussão, contrapõe-se a racionalidade instrumental na alocação de recursos públicos escassos para a saúde versus o valor intrínseco do cuidado permanente devido ao ser humano, especialmente ao idoso. Afloram aqui noções carregadas de preconceitos e estigmas capazes de anular a construção de uma consciência ampla sobre necessidade e importância da saúde bucal, desvinculada de faixas etárias e da expectativa de vida. Vale dizer, de uma consciência de cuidado à saúde bucal por todo o curso da vida.

O acúmulo de informação parece também se apresentar contraditório no que diz respeito à realização de procedimentos de (auto)cuidado à saúde bucal. Possuir informação é considerado fundamento para a realização das práticas de cuidado, mas não constitui elemento suficiente. É necessário mais que informação disponível e de qualidade: a pessoa possuidora da informação precisa processá-la, incorporá-la, para que seja transformada em ação. Esse procedimento é conflituoso, à medida que outras variáveis, como educação formal e informal, renda, classe social, oportunidades de vida, estilos de vida, ambiente, consciência, necessidade, entre outras, jogam um papel igualmente relevante na adoção das práticas de (auto)cuidado. A informação disponível não se distribui nem é assimilada homogeneamente por todas as pessoas. Para tanto, são necessários o desenvolvimento de recursos prévios para possibilitar a aquisição da informação disponível e, também, o seu processamento e tradução em práticas.

$\mathrm{Na}$ interação ocorrida entre pessoas durante a execução dos procedimentos de cuidado à saúde bucal do idoso institucionalizado, são gerados sentimentos contraditórios, como revelou o estudo, tanto desencadeados nos idosos quanto nos cuidadores e em outros profissionais envolvidos. Cuidar da saúde bucal das pessoas idosas desperta emoções de toda ordem. Traz felicidade, alegria, prazer e otimismo, sentimentos bons, resultantes da sensação de dever cumprido e do bem-fazer o bem, a si mesmo e ao outro. Faz florescer sentimentos de gratidão, reconhecimento, amizade, na pessoa cuidada. De outro lado, simultaneamente, afloram sensações de angústia, tristeza, medo, dor, nojo e 
frustração, gerados por traumas anteriormente vivenciados; pela observação da péssima condição de saúde bucal dos idosos; pelo contato íntimo com a boca e as próteses dentárias; pela sensação de não saber precisamente o que fazer; pela percepção de ineficácia das práticas; pela pouca valorização dos procedimentos; e pela falta de demonstração de resultados positivos para o idoso.

Os dados que circulam entre os participantes da pesquisa ora referida continuam, assim, revelando a convivência com o contraditório. $\mathrm{O}$ cuidado à saúde bucal, embora praticado com diligência técnica, em favor do bem-estar do idoso, também é capaz de provocar reações iradas, rispidez e até mesmo malefícios. Tais reações podem surgir quando se considera o procedimento desagradável ou que prejudica seu conforto momentâneo, interfere na sua autonomia, causa-lhe dor ou é realizado contra sua vontade.

Os atores em cena: cuidadores de idosos, dirigentes de ILP e o Estado/ governo, na figura dos seus funcionários, sejam gestores e/ou profissionais da saúde, são todos agentes ativos do processo de cuidado à saúde bucal. Por meio da sua atuação, as práticas de cuidado à saúde bucal tornam-se reais, significativas e consistentes ou, ao revés, inconsistentes, sem sentido e inexistentes. Encerram no seu comportamento as circunstâncias e o propósito da ação ou da omissão. Ainda que a retórica desses atores corresponda ao discurso do "dever-ser", nem sempre a prática lhe é correspondente. A omissão, a incompletude, a não-integralidade, a não-eqüidade das ações, a falta de acesso aos serviços, o desrespeito às diferenças e às necessidades especiais dos idosos, a perpetuação de estigmas e o mascaramento do problema ocorrem com freqüência e são faces nada glamurosas do processo de cuidar. É a contradição entre o "dever-ser" e a dura realidade.

Cuidadores de idosos e outros profissionais da saúde não conseguem definir/decidir se o cuidado à saúde bucal incorpora elementos que o caracterizam como fácil ou de difícil execução. Considerar fácil a realização das práticas de cuidado à saúde bucal ao idoso é relacioná-las e compará-las a qualquer outro procedimento básico de (auto)cuidado que preserve a vida e a saúde, excluindo a possibilidade de deixar de praticá-las, transformando-as em ações cotidianas e reduzindo-as à simplicidade de outros procedimentos. Porém, ainda que as técnicas de cuidado sejam simplificadas e, portanto, factíveis, são muitas as dificuldades que rodeiam o processo, em todos os níveis: interpessoal, intra e interinstitucional, o que frustra o acontecer do cuidado. O fácil e o difícil são propriedades concomitantes do cuidado à saúde bucal que, no seu antagonismo, 
representam uma contradição própria daquilo que condiciona as práticas típicas dirigidas à população idosa.

O cuidado à saúde bucal ora estudado, quando realizado por terceiros, é praticado por profissionais de áreas da saúde. Portanto, por pessoas que em algum momento e em diferentes níveis de formação obtiveram conhecimentos acadêmicos para desenvolvimento de habilidades específicas de cuidado em suas esferas de competência. Esta formação, quando analisada pelo ângulo dos profissionais de Enfermagem, demonstra-se incompleta, não atendendo às necessidades cotidianas de cuidado à saúde bucal apresentadas pelos idosos. Interessante anotar que os conhecimentos utilizados como base para fundamentar suas práticas de cuidado à saúde bucal são mais de caráter empírico, popular, do que de caráter técnico-profissional. Conhecimentos com origem na própria família do profissional e nos meios de comunicação, mais do que em espaços formais e acadêmicos, ou mesmo fruto de treinamento e capacitação específicos.

Seguindo essa direção, também os profissionais da Odontologia ressentemse de não possuírem sólidos conhecimentos acadêmicos sobre o contingente idoso e os cuidados a sua saúde bucal. Assim, aqui a contradição se estabelece ante a intervenção necessária do profissional e a sua sujeição à falta de conhecimentos específicos proclamados por evidências científicas. Tal fato diminui seu poder de ação e o valor dado ao cuidado à saúde bucal do idoso.

Não se pode afirmar serem inexistentes algumas atividades/atitudes internas das ILP para efetivar as práticas de cuidado à saúde bucal aos idosos residentes, principalmente por parte dos cuidadores auxiliares e técnicos de Enfermagem. No bojo de suas responsabilidades, aparece a dicotomia do fazer/não-fazer cotidiano, estando representada pelos esquecimentos, omissões, imprecisão na delegação das tarefas, falta de materiais e instrumentos apropriados, falta de recursos e mesmo comportamentos negligentes e práticas ineficazes.

O cuidado à saúde bucal deveria ser praticado dentro de padrões de continuidade e constância, independentemente de fatores individuais ou coletivos, pessoais ou organizacionais, não devendo ser influenciado ou ficar vulnerável às circunstâncias ou contingências da vida dos próprios idosos, das instituições ou dos serviços de saúde externos à instituição. Entretanto, a descontinuidade do cuidado é uma característica muito presente. Embora considerada ruim e não desejada, a descontinuidade é originada/justificada por comportamentos inconstantes dos idosos, por posturas e atitudes não padronizadas dos cuidadores 
e outros profissionais da saúde, pela falta de comprometimento das instituições e pela ausência da intervenção do poder público para além de ações/normas eventuais, quando existentes.

Os participantes da pesquisa confirmam ser necessárias e indispensáveis as práticas de cuidado à saúde bucal de idosos institucionalizados. Todavia, elas não ocupam lugar prioritário ou de destaque na pauta das atividades de higiene e conforto das instituições, da mesma forma que não é dada prioridade à resolução de problemas bucais, até o momento em que aparecem sintomas e queixas pelo idoso. As práticas de cuidado à saúde bucal não raro são dispensadas, substituídas ou deslocadas para o final do rol das prioridades.

$\mathrm{O}$ cuidado à saúde bucal em uma ILP ocorre entre a ordem e a desordem. Em uma instituição de vida coletiva, costuma haver normas de convivência e certa ordem em prol da eficiência dos serviços. Isto implica limitações à liberdade individual, mas também assegura respeito aos direitos de cada um. Os procedimentos de cuidado à saúde, no ambiente coletivo de viver, requerem persistência, programação e ordenamento. Desse modo, cria-se um código de conduta pelo qual a pessoa cuidada e o cuidador sabem o momento em que cumprirão suas responsabilidades, proporcionando ou recebendo cuidados.

Se, de um lado, programação e disciplina permitem aos cuidadores e demais empregados saber o que e quando fazer, facilitando o seu trabalho, tornando-o mais eficiente, de outro tolhem a flexibilidade e a criatividade muitas vezes necessárias para que o cuidado, além de eficiente, se torne eficaz. Programação e disciplina podem prenunciar que todos os procedimentos básicos (alimentação, higiene, conforto e administração de medicamentos, por exemplo) sejam realizados a contento. Porém, os casos especiais, as diferenças são mais difíceis de serem percebidas e satisfeitas. No que se refere ao cuidado à saúde bucal, os dados revelam uma desorganização das práticas. Prevalece a inexistência de uma programação de trabalho de promoção da saúde. As normas são superficiais e não há protocolos de atuação em saúde bucal. Assim, embora os requisitos "plano", "ordenação" e "disciplina" pudessem orientar as ações, estas resultam das circunstâncias e da mera repetição inconsciente. O modo particular de atuação de cada cuidador fora de um protocolo e de critérios que permitam avaliação não significa o protagonismo de uma ação flexível e adaptativa. Nesse caso, se trata de desorganização mesmo. Aqui nos referimos à contradição que se estabelece entre uma ação rotinizada tecnicamente e a necessidade de flexibilidade e adaptabilidade em face da diversidade de situações 
de cuidado com que o cuidador se defronta.

As instituições geralmente preestabelecem como procederão quando surgir a necessidade de buscar atenção odontológica na rede pública para um residente. Assim, supõem a disponibilidade de serviços públicos de saúde bucal, de suas estruturas e operações, quando se apresentam solicitando atendimento para o idoso. Aqui também se coloca a contradição. Ela se estabelece por conta da dificuldade de acesso, limitação de procedimentos, insuficiência de profissionais, baixa condição de resolutividade e poucas atitudes pró-ativas. As regras de funcionamento dos centros de saúde, ante os direitos dos idosos, são cosméticas. Quando muito ordenam filas, organizam agendas e, ainda assim, há restrições de horários. Ao mesmo tempo em que as ILP têm o direito de bater às portas dos serviços de saúde bucal disponíveis na rede pública, não lhes é garantido o serviço no momento em que seus residentes necessitam. Ademais, a prestação de serviços públicos na atenção básica mostra-se inadequada às demandas dos idosos. Os procedimentos odontológicos disponíveis são insuficientes para a realidade epidemiológica da população idosa atual, que necessita de outros tipos de procedimentos, mais complexos, além daqueles minimamente oferecidos. Rompem-se, com isso, os princípios da integralidade.

A garantia de acesso ao pronto-atendimento, ou seja, a prioridade dos idosos, fixada em lei, esbarra na dificuldade real de atenção quando necessita de cuidado integral à saúde bucal, que contemple suas condições epidemiológicas. Os serviços públicos mostram-se despreparados para suprir essa demanda, juridicamente assegurada, mas não traduzida em acessibilidade e resolutividade. $\mathrm{O}$ acesso universal aos serviços, a garantia e a oportunidade de tratamentos, enfim, o efetivo atendimento à saúde bucal do idoso, ainda são dados no plano virtual. As contradições aparecem flagrantemente entre os planos jurídicoinstitucional e o plano das políticas públicas implementadas: há um abismo entre o plano normativo, que assegura o direito à provisão de atenção à saúde bucal aos idosos, e sua efetiva oferta.

O cuidado à saúde bucal aos idosos ocorre nas esferas individuais e coletivas de ação/interação. Ele é individual por acontecer no momento em que a própria pessoa, ou por ação do cuidador ou outro profissional da saúde, realiza passo a passo, de modo singular e de acordo com as necessidades, os procedimentos de cuidado. Também é coletivo, na medida em que for planejado para a população de idosos enquanto um coletivo, englobando todos nas suas mais diferentes condições de renda, vida e saúde, sendo universalmente 
abrangente. Pensar o cuidado à saúde bucal nas ILP para idosos é, também, aprender a conviver, lidar e integrar esse conflito entre a maximização do bemestar individual versus a maximização do bem-estar coletivo. Contradição forte, pois o somatório da maximização do bem-estar de cada indivíduo não implica o máximo de bem-estar coletivo. A incongruência entre o singular e o plural, entre o um e os muitos que necessitam de tipologias de cuidado diferenciadas e ao mesmo tempo homogêneas, constitui um desafio permanente.

Percebe-se uma difusa noção de responsabilidade nas esferas individual, profissional, institucional e estatal/governamental com relação ao cuidado à saúde bucal. Todos se reconhecem como responsáveis, principalmente pela consciência de que o "não-fazer" e suas consequiências negativas trazem prejuízo para a saúde e vida do idoso. Entretanto, esse sentir a responsabilidade nem sempre é capaz de promover ações transformadoras que resultem em práticas de cuidado dotadas de eficácia. $\mathrm{O}$ sentimento difuso de responsabilidade não carrega força suficiente para modificar as práticas inadequadas de cuidado à saúde bucal. Ainda assim, esse sentimento de responsabilidade é positivo, pois é indispensável para o florescimento de idéias que melhorem os procedimentos.

A saúde bucal e os cuidados a ela associados são interpretados como um direito dos cidadãos que deve ser garantido pelo Estado por meio de programas ou políticas públicas inclusivas e universais, que não diferenciem a população quanto à possibilidade de acesso e tipo/qualidade de cuidado/ tratamento. Por outro lado, contrapõe-se um regime privado de provisão e produção de serviços odontológicos que disputa o segmento da demanda com capacidade de pagar o preço. Este outro universo é hoje ainda mais complexo, devido à intermediação de organizações empresariais (planos de saúde).

É evidente o modo como os cuidados à saúde bucal são vistos e tratados como uma mercadoria de consumo. Assim, só podem deles fazer uso, ou se beneficiar de suas tecnologias, aqueles idosos que podem pagar o preço privado dos serviços prestados. Os serviços públicos, seja na atenção básica ou na média complexidade, não oferecem um plano de atenção individual, nem fornecem uma gama mais ampla de procedimentos odontológicos, como os reabilitadores. Assim circunscrevem, limitam a prática da assistência odontológica, tornando-a pouco conservadora e até mesmo mutiladora.

Vale dizer, essas restrições de atenção serão indutoras de uma constante demanda, cuja extração dentária é a única porta de saída. Pode-se questionar se o objetivo último dessa prática é a qualidade de vida das pessoas ou a morte, 
pela incapacidade de responder em longo prazo às necessidades que derivarão da realização de procedimentos "radicais", como a extração dentária. A ausência dentária pode acarretar graves consequiências que, se levadas ao extremo, podem ser fatais, especialmente se considerarmos o contexto urbano de vida e saúde da pessoa idosa. Esse cenário no setor privado, não tanto pela limitação do rol de procedimentos, apresenta-se mergulhado em estigmas e preconceitos sobre a pessoa idosa que também contribuem para a perpetuação de práticas inadequadas.

\section{Incorporando posturas de melhores práticas}

O condicionamento aos três axiomas da lógica identitária (identidade, não-contradição, terceiro-excluído) produz um pensamento reducionista. Pensamento que esconde a diversidade, a incerteza, as solidariedades, as retroações, a complexidade das organizações, as emergências, os sistemas, as totalidades, suscitando concepções unidimensionais, compartimentalizadas da realidade. Logo, esta lógica se articula perfeitamente com tudo o que é isolável, fragmentado, determinista. Ao não possibilitar a abertura para a compreensão do complexo, torna-se um instrumento a serviço de uma "inteligibilidade utilitária", correspondendo às nossas inclinações práticas de ultrapassar/desconsiderar o incerto e o ambíguo para produzir um diagnóstico inequívoco e preciso (MORIN, 1992).

Para resolver o paradoxo e lidar com os elementos contraditórios que eles representam, é necessário, segundo Morin (1992), tomar uma posição externa ao sistema estudado e estabelecer um metaponto de vista que supere o paradoxo. Assim, a contradição poderia ser ultrapassada graças à introdução de um metaponto de vista complexo, onde a certeza absoluta que se pressupõe trazer o silogismo seria agora substituída por uma plausibilidade ou probabilidade.

A presença do pensamento complexo, não retilíneo, contribui para a apreensão não-mutilante da realidade, tornando visíveis as incertezas, ambigüidades, contradições e paradoxos. Toda lógica que exclui a ambigüidade expulsa a incerteza e ignora a contradição é insuficiente, reducionista, e não dá conta da compreensão ampla do fenômeno.

Uma das tarefas do pensamento complexo é saber tratar, questionar, salvaguardar as contradições. Se de um lado a razão, o raciocínio, pede que desapareçamos com a contradição, de outro também pede que as 
salvaguardemos para escapar do pensamento estéril (MORIN, 1992 e 2005).

Embora neste texto, em alguns momentos, formulem-se reflexões particularizadas sobre o cuidado à saúde bucal, isso não significa abdicação da unicidade que envolve o conceito de cuidado. Ao contrário, entende-se imprescindível que as práticas de promoção da saúde bucal estejam incorporadas às ações individuais e coletivas de cuidado da saúde em geral. Assim, numa visão de promoção da saúde, não-funcionalista, valoriza-se o cuidado tanto na sua dimensão técnica quanto teórico-filosófica e políticoética, integrando o todo nas partes e as partes no todo. Essa lógica também é assimilável no pensamento complexo, do mesmo modo que este incorpora os elementos de contradição.

O todo tem qualidades/propriedades que não são encontradas nas partes, e certas qualidades/propriedades das partes podem ser inibidas pelas restrições provenientes do todo. A reunião de ambos é maior que a simples soma; o resultado expande as relações no bojo da complexidade. Assim, no fenômeno complexo os elementos são diferentes, mas inseparáveis, constitutivos do todo num tecido independente, interativo e inter-retroativo (MORIN, 2002). Saúde e saúde bucal circulam entre o todo e as partes, entre as partes e o todo, no fenômeno de cuidar na perspectiva do envelhecimento saudável. E, neste movimento circular permeado de contradições, nenhuma é mais importante ou sobressalente que a outra, mas estão intrinsecamente ligadas, estabelecendo relações mútuas e influências recíprocas.

A busca por melhores práticas como metaponto de vista a ser alcançado indica transformações em direção a um novo estágio, construído a partir do reconhecimento das contradições passadas e presentes. A salvaguarda das contradições ajuda a evitar proposições infrutíferas, despidas de efetividade. Daí que as transformações por via da adoção de uma postura pró-melhorias contínuas prometem um avanço sustentado na qualidade do cuidado.

As melhores práticas no cuidado à saúde bucal referem-se às decisões e escolhas planejadas, entendidas como desafio, considerando o todo do fenômeno, numa postura de um melhor-fazer-melhor. Trata-se de percorrer um caminho que oferece riscos e incertezas, mas que direciona as energias para novos estágios. Segundo Morin (2002), assim que se empreende uma ação complexa, esta começa a se distanciar da intenção inicial, entrando em interação com o meio ambiente e tomando rumo incerto. Por isso se requer seguir as ações, corrigi-las e até eliminá-las, se necessário, pois carregam em si 
a complexidade, o aleatório, o inesperado, o imprevisto, a derivação e as transformações. Portanto, implementar posturas de melhores práticas exige controle, avaliação e reprogramação.

O cuidado à saúde bucal do idoso institucionalizado, como se viu, apresenta-se permeado de contradições, tanto nas condições em que se estabelece, como em suas potencialidades para construir uma saúde bucal condizente com um viver saudável. A partir dessa constatação, propõe-se uma transformação nos modos correntes de gerenciamento. Essa transformação se inicia com o resgate do valor do cuidado à saúde bucal nas suas dimensões teórico-filosófica e político-ética, e sua integração na base das concepções de gestão, reforçando, conseqüentemente, sua dimensão técnica. Neste contexto, a idéia-força de melhoria contínua, traduzida em melhores práticas de cuidado, permearia as estruturas e os processos que compõem a promoção do cuidado à saúde bucal dos idosos. A incorporação de comportamentos gerenciais de melhoria contínua dessas práticas de cuidado, na perspectiva do viver e envelhecer com saúde bucal, constitui estratégia capaz de tornar plausível ultrapassar um estágio de contradição como o aqui revelado em direção a outro estágio qualitativamente superior.

\section{Referências}

ERDMANN, Alacoque L. Sistemas de cuidados de Enfermagem. Pelotas: Editora Universitária/UFPel, 1996. 148p. (Série Teses em Enfermagem).

GLASER, Barney; STRAUSS, Anselm. The discovery of grounded theory: strategies for qualitative research. New York: Aldine de Gruyter, 1967.

GLASER, Barney; HOLTON, Judith. Remodeling grounded theory. The Grounded Theory Review, v. 4, n. 1, p. 1-24, Nov. 2004.

GLASER, Barney. Grounded theory perspective III: theoretical coding. Chicago: Sociology Press; 2005.

MELLO, Ana Lúcia S. F. Promovendo o cuidado à saúde bucal do idoso: revelando contradições no processo de cuidar e incorporando melhores práticas a partir do contexto da instituição de longa permanência para idosos. 2005. 319p. Tese (Doutorado em Enfermagem) - Curso de Pós-graduação em Enfermagem, Universidade Federal de Santa Catarina, Florianópolis, 2005. 
MORIN, Edgar. Ciência com consciência. Rio de Janeiro: Bertrand Brasil, 2005. . La cabeza bien puesta: repensar a reformar, reformar o pensamiento. Buenos Aires: Nueva Visión, 1999. . O método IV: as idéias... Mira-Sintra: Publ. Europa América, 1992. . Os sete saberes necessários à educação do futuro. São Paulo: Cortez, 2002.

\section{NOTAS}

${ }^{1}$ Baseado na tese Promovendo o cuidado à saúde bucal do idoso: revelando contradições no processo de cuidar e incorporando melhores práticas a partir do contexto da instituição de longa permanência (MELLO, 2005), de autoria de Ana Lúcia S. F. de Mello e orientada por Alacoque L. Erdmann. Apoio CAPES/CNPq.

- Cirurgiã-dentista. Doutora em Enfermagem - área de concentração Filosofia, Saúde e Sociedade - UFSC. Endereço eletrônico: alfm@terra.com.br.

- Enfermeira. Doutora em Filosofia da Enfermagem - UFSC. Professora do Programa de Pósgraduação em Enfermagem - UFSC. Pesquisadora 1A CNPq. 


\section{Unveiling Contradictions and Incorporating Best Practices in the Elderly's Oral Health}

This paper presents and discusses the contradictions in the process of taking care of elderly's oral health in the perspective of the complex care and the logic of complexity, based on the Grounded Theory methodology. Nineteen people participated in the study, among elderly residents of long-term institutions, caregivers, directors, dentists and public health services managers. The emergent central category corresponds to the process of "Promoting oral health of the elderly in the context of long-term care institutions". Two levels were identified: one in which contradictions in the process of taking care of the elderly's oral health keeps the poor epidemiological status; and other, superior, that incorporates best practices in the structures and in the processes that form the promotion of the elderly's oral health care. To treat the elements that form the contradiction, without eliminating or disrespecting them, but working, looking for the improvement of each one, allows overcoming the contradiction, outlining the obstacle it represents. In the same way, the adoption of best practices can be considered a meta-viewpoint expressed to the elderly oral health care system, able to overcome the contradiction levels, as it is revealed here.

Key words: Elderly; care; oral health; theory of complexity. 